Original Article

\title{
Evaluation of oxygen uptake adjusted by skeletal muscle mass in cardiovascular disease patients with type 2 diabetes
}

\author{
Nana Takao, MA ${ }^{1,2)^{*}}$, Junji Iwasaka, MD, PhD ${ }^{3)}$, Satoshi Kurose, $\mathrm{PhD}^{4}$, \\ Takumi Miyauchi ${ }^{1,2)}$, Astuko Tamanoi ${ }^{2)}$, Ryota Tsuyuguchi, $\mathrm{PhD}^{1)}$, Aya Fujit, MA ${ }^{1,2)}$, \\ Hiromi Tsutsumi ${ }^{4)}$, Yutaka Kimura, MD, $\mathrm{PhD}^{2,4)}$ \\ 1) Department of Health Science, Graduate School of Medicine, Kansai Medical University: 2-5-1 \\ Shinmachi, Hirakata 573-1010, Japan \\ 2) Health Science Center, Kansai Medical University Hospital, Japan \\ 3) Department of Medicine II, Kansai Medical University, Japan \\ 4) Department of Health Science, Kansai Medical University, Japan
}

\begin{abstract}
Purpose] We aimed to evaluate oxygen uptake adjusted by total skeletal muscle mass in patients with cardiovascular disease with or without type 2 diabetes mellitus. [Participants and Methods] The participants included 54 males $\geq 50$ years of age without heart failure who underwent cardiopulmonary exercise testing during cardiac rehabilitation. We divided the participants into two groups: patients with type 2 diabetes mellitus (DM group) and patients without type 2 diabetes mellitus (NDM group). [Results] We found no significant differences in age, weight, fat mass, or skeletal muscle mass between the groups. There were also no differences in cardiac function, body composition, and heart rate response. The DM group showed significantly lower peak oxygen uptake values adjusted by skeletal muscle mass, despite the absence of significant differences in skeletal muscle mass. A significant positive correlation was found between peak oxygen uptake and age, weight, and skeletal muscle mass. Stepwise regression analysis revealed that age, skeletal muscle mass, and medical history of diabetes were independent predictors of absolute peak oxygen uptake. [Conclusion] Peak oxygen uptake adjusted by skeletal muscle mass in patients with cardiovascular disease and type 2 diabetes mellitus is lower than that in those without type 2 diabetes mellitus. Key words: Cardiopulmonary exercise testing, Peak oxygen uptake, Skeletal muscle mass
\end{abstract}

(This article was submitted Aug. 25, 2020, and was accepted Nov. 2, 2020)

\section{INTRODUCTION}

Cardiopulmonary exercise testing (CPX) is a useful way to evaluate prognosis, risk of metabolic diseases, condition of diseases, determination of exercise intensity, and efficacy of exercise therapy ${ }^{1-5}$. The most popular marker is peak oxygen uptake $\left(\mathrm{VO}_{2}\right)$. Low peak $\mathrm{VO}_{2}$ is an independent risk factor for cardiovascular and metabolic diseases ${ }^{6-8}$. Recently, it has been reported that total skeletal muscle mass (SMM) is associated with prognosis in patient with cardiovascular disease (CVD) ${ }^{9}$, and its evaluation is also important.

Although $\mathrm{VO}_{2}$ adjusted by body weight $\left(\mathrm{VO}_{2} / \mathrm{w}\right)$ is used to evaluate the exercise capacity, body weight includes fat mass and SMM. $\mathrm{VO}_{2}$ is not proportional to body weight ${ }^{10)}$ because it is often greatly affected by the amount of fat. In previous studies, it was reported that $\mathrm{VO}_{2}$ per lean body mass was more effective for evaluating exercise capacity in healthy subjects, obese patients, metabolic syndrome patients, and patients during cardiac rehabilitation, because peak $\mathrm{VO}_{2} / \mathrm{w}$ only standardizes differences in body size ${ }^{9,11-13)}$. In addition, the decrease in $\mathrm{VO}_{2}$ due to aging and gender is also associated with an

*Corresponding author. Nana Takao (E-mail: takaonan@hirakata.kmu.ac.jp)

(C2021 The Society of Physical Therapy Science. Published by IPEC Inc.

(c) (i) $(-)$ This is an open-access article distributed under the terms of the Creative Commons Attribution Non-Commercial No Deriva-

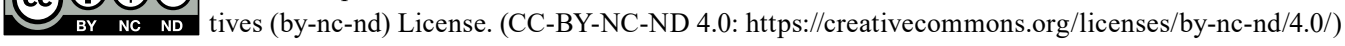


increase in percent body fat mass and decrease in percent skeletal muscle mass. Many studies have evaluated $\mathrm{VO}_{2}$ in cardiac rehabilitation patients ${ }^{14-16)}$. Previous reports have suggested that peak $\mathrm{VO}_{2}$ is frequently impaired in CVD patients with type 2 diabetes $(\mathrm{T} 2 \mathrm{DM})^{17,18)}$. These reports measured $\mathrm{VO}_{2} / \mathrm{w}$ in patients with $\mathrm{CVD}$. Nevertheless, there are no studies that $\mathrm{VO}_{2}$ adjusted by $\mathrm{SMM}\left(\mathrm{VO}_{2} / \mathrm{SMM}\right)$ in CVD patients with T2DM. Therefore, the aim of this study was to evaluate $\mathrm{VO}_{2} / \mathrm{SMM}$ in CVD patients with or without T2DM.

\section{PARTICIPANTS AND METHODS}

This study was approved by the Kansai Medical University Ethics Committee (approval no. 2017135). The main aims, details, and risks were explained to the participants, all of whom provided written informed consent prior to participating.

The participants were 54 male cardiac rehabilitation outpatients, aged $\geq 50$ years, who underwent CPX between April 2013 and February 2017. To eliminate disparities due to cardiac and pulmonary function, we excluded patients with heart failure or with chronic obstructive pulmonary disease and other lung diseases. Patients who were undergoing hemodialysis, those with pacemakers, and those who discontinued CPX for reasons other than symptomatic limits were also excluded. All procedures performed in studies involving human participants were under both the ethical standards of the Kansai Medical University Ethics Committee and 1964 Helsinki declaration and its later amendments or comparable ethical standards.

The basic characteristics and medical histories, including the diagnosis of T2DM, were obtained from the medical records. The participants were divided into two groups: patients with $\mathrm{HbA} 1 \mathrm{c} \geq 6.5 \%$ (based on the results of biochemical tests) and/ or who received oral diabetes drugs were classified as the T2DM group (DM group); the rest were allocated to the group without T2DM (the NDM group).

Body composition was measured using an InBody720 body composition analyzer (InBody, Seoul, Korea). The validity of this bioelectrical impedance analysis has been documented in previous studies ${ }^{19,20)}$.

Echocardiographic studies and blood examinations were performed before the cardiac rehabilitation program. Those results were obtained from the medical records. Casual blood was analyzed to determine glucose and glycosylated hemoglobin (HbAlc) levels, lipid profiles, hemoglobin, hematocrit, creatinine, estimated glomerular filtration rate, and amino-terminal pro-brain natriuretic peptide (NT-proBNP) levels. Left ventricular ejection fraction (LVEF), left atrial dimension, early diastolic transmitral flow velocity (E), the mitral annular velocity at the early diastolic phase on tissue Doppler (e'), E/e', and the ratio of transmitral early and late peak filling rate (E/A) were evaluated using echocardiographic studies. Patients with an LVEF $<60 \%$ and an NT-proBNP $>200 \mathrm{pg} / \mathrm{mL}$ were excluded as they were to have heart failure ${ }^{21)}$.

For the cardiopulmonary exercise testing, a symptom-limited exercise stress test, using the ramp method, was conducted using an expiration gas analyzer (AE300S; Minato Medical Science Co., Ltd., Osaka, Japan) and an ergometer cycle (AEROBIKE 75XL; Combi, Tokyo, Japan) with a 12-lead electrocardiogram. After a 5-min rest on the ergometer, the exercise began with a 4-min warm-up at 10-20 watts and $50 \mathrm{rpm}$, followed by the 10-20-watt ramp method. Heart rate $(\mathrm{HR}), \mathrm{VO}_{2}$, and carbon dioxide excretion volume $\left(\mathrm{VCO}_{2}\right)$ were measured at the point of rest, warm-up, anaerobic threshold (AT), and maximum oxygen uptake (peak $\mathrm{VO}_{2}$ ) using the breath-by-breath method. The AT was determined using the V-slope method. Peak $\mathrm{VO}_{2}$ and work rate (WR) were defined as the peak values during incremental exercise. These results were used to calculate 1) respiratory exchange ratio $\left(\mathrm{R}=\mathrm{VCO}_{2} / \mathrm{VO}_{2}\right)$, an energy indicator; 2) $\mathrm{VE}$ (minute ventilation) $/ \mathrm{VCO}_{2}$ slope, a ventilation efficiency indicator; 3) $\mathrm{O}_{2}$ pulse $=\mathrm{VO}_{2} / \mathrm{HR}$, a pulse output indicator; 4) change in $\mathrm{VO}_{2} /$ change in $\mathrm{WR}\left(\Delta \mathrm{VO}_{2} / \Delta \mathrm{WR}\right)$, a cardiac function indicator; and 5) change in heart rate/change in work rate $(\Delta \mathrm{HR} / \Delta \mathrm{WR})$, an autonomic nerve indicator. AT and peak $\mathrm{VO}_{2}$ were calculated by adjusting for both SMM and weight.

All statistical analyses were conducted using SPSS software version 23.0 for Windows (SPSS Inc., Chicago, IL, USA). The measured values are expressed as mean \pm standard deviation. Normal distribution was confirmed using the Shapiro-Wilk test. The unpaired t-test and the $\chi^{2}$ test were used for inter-group comparisons. Pearson's correlation coefficients and stepwise multiple regression analyses were used to measure peak $\mathrm{VO}_{2}$ and peak $\mathrm{VO}_{2} / \mathrm{SMM}$. All tests were two-sided, and a value of $\mathrm{p}<0.05$ was considered significant.

\section{RESULTS}

The characteristics of the participants are shown in Table 1. There were no significant differences in terms of age, weight, and \%fat between the two groups. The DM group had significantly higher body mass index $\left(24.5 \pm 3.0 \mathrm{vs} .22 .7 \pm 2.5 \mathrm{~kg} / \mathrm{m}^{2}\right.$, $\mathrm{p}=0.034$ ). The DM group showed significantly higher HbA1c and blood sugar levels. There were no significant differences in terms of hepatic function, lipid metabolism, or renal function. There were also no significant differences in echocardiography findings, including the cardiac function indicators LVEF and NT-proBNP. A significant difference was found only for administration of oral anti-diabetic drugs (84.6\% [DM group] vs. $0.0 \%$ [NDM group], $\mathrm{p}<0.001)$. There were no differences in terms of other orally administered drugs, including anti-hypotensive and lipid-lowering agents or insulin therapy.

Body composition profiles are shown in Table 2. No significant differences were seen between the DM and NDM groups in terms of SMM, and those of the arms, trunk, and legs. No significant difference was found for fat mass.

The CPX results are shown in Table 3. Peak $\mathrm{VO}_{2} / \mathrm{w}$ was significantly lower in the DM group (DM: $19.1 \pm 3.4$ vs. NDM: $22.6 \pm 4.7 \mathrm{~mL} / \mathrm{kg} / \mathrm{min}, \mathrm{p}=0.017$ ). No significant differences were seen in the AT R or the peak R (AT: $0.89 \pm 0.04 \mathrm{vs} .0 .90 \pm$ 
Table 1. Clinical characteristics of the study groups

\begin{tabular}{|c|c|c|c|}
\hline & $\mathrm{DM}(\mathrm{n}=13)$ & $\operatorname{NDM}(n=41)$ & p-value \\
\hline Age (years) & $68.6 \pm 7.0$ & $67.6 \pm 7.1$ & 0.665 \\
\hline Weight (kg) & $66.4 \pm 9.5$ & $63.8 \pm 9.7$ & 0.407 \\
\hline $\operatorname{BMI}\left(\mathrm{kg} / \mathrm{m}^{2}\right)$ & $24.5 \pm 3.0$ & $22.7 \pm 2.5$ & $0.034 *$ \\
\hline$\%$ Fat $(\%)$ & $25.0 \pm 5.0$ & $22.2 \pm 5.6$ & 0.113 \\
\hline LVEF (\%) & $68.5 \pm 6.7$ & $68.7 \pm 5.8$ & 0.928 \\
\hline LAD (mm) & $39.4 \pm 7.2$ & $36.9 \pm 4.9$ & 0.157 \\
\hline$e^{\prime}(n=13 / 36)(m / s e c)$ & $0.06 \pm 0.01$ & $0.08 \pm 0.08$ & 0.310 \\
\hline$E / e^{\prime}(n=13 / 36)$ & $11.5 \pm 1.9$ & $10.1 \pm 3.8$ & 0.107 \\
\hline $\mathrm{E} / \mathrm{A}$ & $0.81 \pm 0.25$ & $0.85 \pm 0.21$ & 0.554 \\
\hline NT-proBNP (pg/dL) & $69.5 \pm 53.6$ & $98.8 \pm 53.7$ & 0.092 \\
\hline $\mathrm{Hb}(\mathrm{g} / \mathrm{dL})$ & $14.4 \pm 1.8$ & $14.3 \pm 1.1$ & 0.838 \\
\hline HbAlc (\%) & $6.6 \pm 0.8$ & $5.7 \pm 0.4$ & $<0.001^{*}$ \\
\hline Glu (mg/dL) & $153.8 \pm 41.5$ & $106.5 \pm 22.1$ & $0.001 *$ \\
\hline $\mathrm{TG}(\mathrm{n}=13 / 40)(\mathrm{mg} / \mathrm{dL})$ & $154.0 \pm 58.1$ & $148.6 \pm 79.3$ & 0.820 \\
\hline HDL-cho $(\mathrm{n}=12 / 41)(\mathrm{mg} / \mathrm{dL})$ & $46.5 \pm 15.3$ & $49.6 \pm 12.3$ & 0.470 \\
\hline LDL-cho $(\mathrm{n}=13 / 40)(\mathrm{mg} / \mathrm{dL})$ & $83.4 \pm 17.9$ & $90.5 \pm 23.5$ & 0.325 \\
\hline Cre (mg/dL) & $0.98 \pm 0.45$ & $0.91 \pm 0.16$ & 0.571 \\
\hline eGFR & $67.9 \pm 22.4$ & $66.7 \pm 12.0$ & 0.848 \\
\hline \multicolumn{4}{|l|}{ History of cardiovascular disease (\%) } \\
\hline Coronary artery disease & 84.6 & 85.4 & 0.947 \\
\hline Myocardial infarction & 46.2 & 53.7 & 0.439 \\
\hline Angina & 38.5 & 31.7 & 0.448 \\
\hline Vascular disorders & 15.4 & 9.8 & 0.574 \\
\hline Thoracic aortic aneurysm & 7.7 & 7.3 & 0.653 \\
\hline Abdominal aortic aneurysm & 7.7 & 2.4 & 0.057 \\
\hline Valve disease & 7.7 & 12.2 & 0.653 \\
\hline Aortic valve stenosis & 0 & 9.8 & 0.430 \\
\hline Mitral valve stenosis & 7.7 & 2.4 & 0.570 \\
\hline \multicolumn{4}{|l|}{ Intervention (\%) } \\
\hline Percutaneous coronary intervention & 76.9 & 70.7 & 0.664 \\
\hline Coronary artery bypass grafting & 7.7 & 14.6 & 0.516 \\
\hline Valve replacement & 7.7 & 12.2 & 0.635 \\
\hline Aortic replacement, endovascular aortic repair & 15.4 & 9.8 & 0.574 \\
\hline
\end{tabular}

Results are expressed as mean $\pm \mathrm{SD}$.

DM: diabetes group; NDM: non-diabetes group; BMI: body mass index; Cre: creatinine; eGFR: estimated GFR; GLU: glucose; HbAlc: hemoglobin Alc; Hb: hemoglobin; HDL-cho: high density lipoprotein cholesterol; HTC: hematocrit; LAD: left anterior descending; LDL-cho: low density lipoprotein cholesterol; LVEF: left ventricular ejection fraction; NT-proBNP: N-terminal proatrial natriuretic peptide; TG: triglyceride.

Table 2. Results of the body composition analysis

\begin{tabular}{lrrc}
\hline & DM $(\mathrm{n}=13)$ & NDM $(\mathrm{n}=41)$ & p-value \\
\hline Total skeletal muscle mass $(\mathrm{kg})$ & $27.1 \pm 3.0$ & $27.1 \pm 3.5$ & 0.965 \\
Arm muscle mass $(\mathrm{kg})$ & $2.7 \pm 0.4$ & $2.8 \pm 0.5$ & 0.735 \\
Trunk muscle mass $(\mathrm{kg})$ & $22.1 \pm 2.4$ & $22.0 \pm 2.7$ & 0.931 \\
Leg muscle mass $(\mathrm{kg})$ & $7.6 \pm 0.9$ & $7.8 \pm 1.1$ & 0.597 \\
Total fat mass $(\mathrm{kg})$ & $16.9 \pm 5.4$ & $15.1 \pm 5.8$ & 0.169 \\
Arm fat mass $(\mathrm{kg})$ & $1.1 \pm 0.4$ & $0.9 \pm 0.5$ & 0.207 \\
Trunk fat mass $(\mathrm{kg})$ & $8.7 \pm 3.2$ & $7.2 \pm 3.2$ & 0.156 \\
Leg fat mass $(\mathrm{kg})$ & $2.5 \pm 0.7$ & $2.2 \pm 0.7$ & 0.174 \\
\hline
\end{tabular}

Results are expressed as mean $\pm \mathrm{SD}$.

DM: diabetes group; NDM: non-diabetes group; 
Table 3. Results of the cardiopulmonary exercise testing

\begin{tabular}{|c|c|c|c|}
\hline & $\mathrm{DM}(\mathrm{n}=13)$ & $\operatorname{NDM}(n=41)$ & p-value \\
\hline AT HR (beat/min) & $91.2 \pm 7.0$ & $90.0 \pm 11.9$ & 0.747 \\
\hline AT RR (times) & $22.3 \pm 3.0$ & $21.9 \pm 3.2$ & 0.694 \\
\hline AT WR (W) & $46.9 \pm 12.2$ & $52.5 \pm 11.4$ & 0.134 \\
\hline AT R & $0.89 \pm 0.04$ & $0.90 \pm 0.05$ & 0.380 \\
\hline $\mathrm{ATVO}_{2}(\mathrm{ml} / \mathrm{min})$ & $794.7 \pm 158.2$ & $835.0 \pm 144.4$ & 0.394 \\
\hline $\mathrm{ATVO}_{2} / \mathrm{w}(\mathrm{ml} / \mathrm{min} / \mathrm{kg})$ & $11.8 \pm 1.6$ & $13.1 \pm 2.4$ & 0.083 \\
\hline $\mathrm{ATVO}_{2} / \mathrm{SMM}(\mathrm{ml} / \mathrm{min} / \mathrm{kg})$ & $29.3 \pm 4.6$ & $30.9 \pm 4.7$ & 0.281 \\
\hline $\mathrm{AT} \mathrm{O}_{2}$ pulse & $8.8 \pm 1.9$ & $9.4 \pm 1.7$ & 0.297 \\
\hline Peak HR (beat/min) & $117.9 \pm 14.1$ & $124.8 \pm 16.4$ & 0.180 \\
\hline Peak RR (times) & $19.2 \pm 5.3$ & $31.3 \pm 4.7$ & 0.181 \\
\hline Peak WR (W) & $96.2 \pm 26.2$ & $111.2 \pm 27.2$ & 0.085 \\
\hline Peak R & $1.09 \pm 0.08$ & $1.14 \pm 0.07$ & 0.060 \\
\hline $\mathrm{PeakVO}_{2}(\mathrm{ml} / \mathrm{min})$ & $1,286.3 \pm 292.0$ & $1,452.1 \pm 319.9$ & 0.103 \\
\hline $\mathrm{PeakVO}_{2} / \mathrm{w}(\mathrm{ml} / \mathrm{min} / \mathrm{kg})$ & $19.1 \pm 3.4$ & $22.6 \pm 4.7$ & $0.017 *$ \\
\hline $\mathrm{PeakVO}_{2} / \mathrm{SMM}(\mathrm{ml} / \mathrm{min} / \mathrm{kg})$ & $47.5 \pm 9.1$ & $53.4 \pm 8.8$ & $0.041^{*}$ \\
\hline Peak O2 pulse & $10.9 \pm 1.9$ & $11.7 \pm 2.2$ & 0.257 \\
\hline $\mathrm{VE} / \mathrm{VCO}_{2}$ slope & $26.0 \pm 4.7$ & $26.3 \pm 4.7$ & 0.800 \\
\hline$\Delta \mathrm{VO}_{2} / \Delta \mathrm{WR}$ & $10.9 \pm 5.6$ & $10.4 \pm 2.9$ & 0.750 \\
\hline$\Delta \mathrm{HR} / \Delta \mathrm{WR}$ & $0.59 \pm 0.51$ & $0.54 \pm 0.18$ & 0.743 \\
\hline
\end{tabular}

Results are expressed as mean $\pm \mathrm{SD}$.

DM: diabetes group; NDM: non-diabetes group; AT: Anaerobic threshold, HR: heart rate, RR: respiratory rate, WR; work rate, $\mathrm{SMM}$ : total skeletal muscle mass; $\mathrm{VO}_{2}$ : oxygen consumption.

Table 4. Correlations and stepwise multiple regression analysis between age, body composition, diabetes mellitus, and peak oxygen uptake

\begin{tabular}{lccccc}
\hline & \multicolumn{2}{c}{ Single regression } & \multicolumn{3}{c}{ Multiple regression } \\
\cline { 2 - 6 } & $\mathrm{r}$ & $\mathrm{p}$-value & $\beta$ & $\mathrm{p}$-value & VIF \\
\hline Age & -0.500 & $<0.001$ & -0.282 & $0.011^{*}$ & 1.184 \\
Weight & 0.462 & $<0.001^{*}$ & -0.097 & 0.615 & 3.804 \\
Total skeletal muscle mass & 0.638 & $<0.001^{*}$ & 0.526 & $<0.001^{*}$ & 1.184 \\
Total fat mass & 0.172 & 0.213 & -0.047 & 0.680 & 1.333 \\
Presence or absence of diabetes & $\mathrm{NA}$ & $\mathrm{NA}$ & 0.204 & $0.042^{*}$ & 1.004 \\
\hline
\end{tabular}

VIF: Variance Inflation Factor; r: correlation coefficient; $\beta$ : standardized partial regression coefficient.

$0.05, \mathrm{p}=0.380$ and peak R: $1.09 \pm 0.08$ vs. $1.14 \pm 0.07, \mathrm{p}=0.060)$. The $\mathrm{DM}$ group showed significantly lower peak $\mathrm{VO}_{2} / \mathrm{SMM}$ (DM: $47.5 \pm 9.1$ vs. NDM: $53.4 \pm 8.8 \mathrm{~mL} / \mathrm{kg} / \mathrm{min}, \mathrm{p}=0.041$ ). However, no significant difference was seen for the $\mathrm{AT}_{\mathrm{VO}} /$ SMM. No significant differences were observed for the $\mathrm{O}_{2}$ pulse at the AT or the peak (AT: $8.8 \pm 1.9$ vs. $9.4 \pm 1.7$, $\mathrm{p}=0.297$ and peak: $10.9 \pm 1.9$ vs. $11.7 \pm 2.2, \mathrm{p}=0.257), \Delta \mathrm{VO}_{2} / \Delta \mathrm{WR}$ (AT: $10.9 \pm 5.6$ vs. peak: $10.4 \pm 2.9, \mathrm{p}=0.750$ ), or $\mathrm{VE} / \mathrm{VCO}{ }_{2}$ slope (AT: $26.0 \pm 4.7$ vs. peak: $26.3 \pm 4.7, \mathrm{p}=0.800$ ). No significant difference was found for $\Delta \mathrm{HR} / \Delta \mathrm{WR}$, the marker of autonomic nerve function (AT: $0.59 \pm 0.51$ vs. peak: $0.54 \pm 0.18, \mathrm{p}=0.743$ ).

Table 4 shows the peak $\mathrm{VO}_{2}$-related factors. A significant negative correlation was found between peak $\mathrm{VO}_{2}$ and age $(\mathrm{r}=-0.500, \mathrm{p}<0.001)$, while significant positive correlations were observed between peak $\mathrm{VO}_{2}$ and weight $(\mathrm{r}=0.462, \mathrm{p}<0.001)$ and between peak $\mathrm{VO}_{2}$ and $\mathrm{SMM}(\mathrm{r}=0.638, \mathrm{p}<0.001)$.

The stepwise multiple regression analysis identified age, SMM, and a medical history of diabetes as independent predictors of peak $\mathrm{VO}_{2}$ regression $(\beta=-0.282 / \mathrm{p}=0.011, \beta=0.526 / \mathrm{p}<0.001$, and $\beta=0.204 / \mathrm{p}=0.042$, respectively).

\section{DISCUSSION}

We observed lower peak $\mathrm{VO}_{2} / \mathrm{w}$ and $\mathrm{VO}_{2} / \mathrm{SMM}$ in CVD patients with T2DM than in those without T2DM. There was no significant difference in body weight between groups; however, the BMI in the DM group was significantly higher than that of the NDM group. Previous studies reported that patients with diabetes have higher body weight and BMI than those without 
diabetes $^{22-24)}$, similar to what we found in this study. However, SMM was not significantly different between groups, and the DM group tended to have a larger amount of body fat. The absolute peak $\mathrm{VO}_{2}$ depends on body weight; however, this value in the DM group tended to be lower than that of the NDM group. In previous studies, weight-corrected $\mathrm{VO}_{2}$ was affected by body fat mass, SMM, and intramyocellular lipid content ${ }^{10-13}$. In other words, lower peak $\mathrm{VO}_{2} / \mathrm{w}$ in the DM group might result from greater body fat mass in the patients with T2DM. Peak $\mathrm{VO}_{2} / \mathrm{SMM}$ excluding the effect of fat mass was also lower in DM group than in the NDM group despite their being no significant difference in the SMM. These findings suggest that the low exercise capacity of diabetic patients may be a problem not only in body fat but also in skeletal muscle quality, and $\mathrm{VO}_{2} / \mathrm{SMM}$ might be useful marker for evaluation to exercise capacity. This is the first report to evaluate peak $\mathrm{VO}_{2} / \mathrm{SMM}$ in CVD patients with or without T2DM. Nevertheless, we only found a difference in peak $\mathrm{VO}_{2} / \mathrm{SMM}$, not in $\mathrm{AT}_{\mathrm{VO}} / \mathrm{SMM}$. The reason was unclear; however, $\mathrm{VO}_{2} / \mathrm{SMM}$ may reflect the quality of skeletal muscle and may represent the condition of skeletal muscle at higher intensity loads than low intensity such as AT level.

$\mathrm{SMM}$ was an independent factor of absolute peak $\mathrm{VO}_{2}$. We selected patients without cardiac systolic dysfunction and respiratory dysfunction to eliminate any unexpected influence of cardiac and respiratory function. The CPX results revealed no significant differences in cardiac function indicators such as $\Delta \mathrm{VO}_{2} / \Delta \mathrm{WR}$ and peak $\mathrm{O}_{2}$ pulse, and autonomic nervous indicators such as $\Delta \mathrm{HR} / \Delta \mathrm{WR}$. These results suggest that the difference of peak $\mathrm{VO}_{2} / \mathrm{SMM}$ might be an effect of skeletal muscle metabolism. Impairment of skeletal muscle metabolism in patients with diabetes ${ }^{25-29)}$ reduces exercise tolerance due to impairment of carbohydrate metabolism, lipid metabolism ${ }^{30)}$, insulin resistance, and insulin sensitivity ${ }^{31-33)}$. Recent genetic research in patients with diabetes revealed a positive correlation between general aerobic capacity and the expression of a coregulated subset of oxidative phosphorylation (OXPHOS) genes (OXPHOS-CR) regulated by PGC-1 $\alpha$, which is positively correlated with general $\mathrm{VO}_{2}{ }^{34)}$. Our finding of a lower peak $\mathrm{VO}_{2}$ in patients with diabetes mellitus may be related to muscle metabolism, as described in previous studies ${ }^{25-34)}$. Endothelial dysfunction in diabetic patients is also one of the causes of impaired exercise tolerance ${ }^{35)}$, however, it could not be evaluated in this study.

There were some limitations in our study. First, the number of participants in the DM group was small. The characteristics of the DM group might become clearer in studies involving a higher number of participants. Multivariate analysis in 13 patients in the DM groups lacked statistical power. Second, this was a cross-sectional study; therefore, we were unable to establish a cause-effect relationship between oxygen uptake and SMM. While the influence exerted by skeletal muscle during exercise has been frequently reported ${ }^{31,32,36-38)}$, future studies are needed to determine how peak $\mathrm{VO}_{2} / \mathrm{SMM}$ changes from before to after exercise intervention. Finally, bioimpedance was used to measure biological components instead of the DEXA method, which is the gold standard for body composition measuring. Nevertheless, we excluded patients with heart failure or prominent edema. We also recorded impedance values in participants.

In conclusion, peak $\mathrm{VO}_{2} / \mathrm{SMM}$ of CVD patients with T2DM was lower than that of patients without T2DM, despite the absence of significant difference in the SMM. The difference of peak $\mathrm{VO}_{2} / \mathrm{SMM}$ may be due to the effect of skeletal muscle metabolism.

\section{Presentation at a conference}

The part of our research was presented in the Annual Meeting of the Japanese Association of Cardiac Rehabilitation 2020.

Funding

The authors declare no funding for this study.

Conflicts of interest

The authors have no conflicts of interest relevant to this article.

\section{ACKNOWLEDGEMENT}

We thank the staff members of the Health Science Center of Kansai Medical University.

\section{REFERENCES}

1) Schwaab B, Kafsack F, Markmann E, et al.: Effects of aerobic and anaerobic exercise on glucose tolerance in patients with coronary heart disease and type 2 diabetes mellitus. Cardiovasc Endocrinol Metab, 2020, 9: 3-8. [Medline] [CrossRef]

2) Takayanagi Y, Koike A, Kubota H, et al.: Pulse wave transit time during exercise testing reflects the severity of heart disease in cardiac patients. Drug Discov Ther, 2020, 14: 21-26. [Medline] [CrossRef]

3) Hama T, Oikawa K, Ushijima A, et al.: Effect of cardiac rehabilitation on the renal function in chronic kidney disease - Analysis using serum cystatin-C based glomerular filtration rate. Int J Cardiol Heart Vasc, 2018, 19: 27-33. [Medline]

4) Smolis-Bąk E, Rymuza H, Kazimierska B, et al.: Improvement of exercise tolerance in cardiopulmonary testing with sustained safety after regular training in outpatients with systolic heart failure (NYHA III) and an implantable cardioverter-defibrillator. Prospective 18-month randomized study. Arch Med Sci, 2017, 13: 1094-1101. [Medline] [CrossRef] 
5) Uithoven KE, Smith JR, Medina-Inojosa JR, et al.: Clinical and rehabilitative predictors of peak oxygen uptake following cardiac transplantation. J Clin Med, 2019, 8: 119. [Medline] [CrossRef]

6) Adachi H: Cardiopulmonary exercise test. Int Heart J, 2017, 58: 654-665. [Medline] [CrossRef]

7) Vest AR, Young JB, Cho L: The metabolic syndrome, cardiovascular fitness and survival in patients with advanced systolic heart failure. Am J Cardiol, 2018, 122: 1513-1519. [Medline] [CrossRef]

8) Fernström M, Fernberg U, Eliason G, et al.: Aerobic fitness is associated with low cardiovascular disease risk: the impact of lifestyle on early risk factors for atherosclerosis in young healthy Swedish individuals — the lifestyle, biomarker, and atherosclerosis study. Vasc Health Risk Manag, 2017, 13: 91-99. [Medline] [CrossRef]

9) Tyrovolas S, Panagiotakos D, Georgousopoulou E, et al.: Skeletal muscle mass in relation to 10 year cardiovascular disease incidence among middle aged and older adults: the ATTICA study. J Epidemiol Community Health, 2020, 74: 26-31. [Medline] [CrossRef]

10) Krachler B, Savonen K, Komulainen P, et al.: Cardiopulmonary fitness is a function of lean mass, not total body weight: the DR's EXTRA study. Eur J Prev Cardiol, 2015, 22: 1171-1179. [Medline] [CrossRef]

11) Hollenberg M, Ngo LH, Turner D, et al.: Treadmill exercise testing in an epidemiologic study of elderly subjects. J Gerontol A Biol Sci Med Sci, 1998, 53: B259-B267. [Medline] [CrossRef]

12) Yokota $\mathrm{T}$, Kinugawa S, Okita K, et al.: Lower aerobic capacity was associated with abnormal intramuscular energetics in patients with metabolic syndrome. Hypertens Res, 2011, 34: 1029-1034. [Medline] [CrossRef]

13) Milani RV, Lavie CJ: The effects of body composition changes to observed improvements in cardiopulmonary parameters after exercise training with cardiac rehabilitation. Chest, 1998, 113: 599-601. [Medline] [CrossRef]

14) Chen YW, Wang CY, Lai YH, et al.: Home-based cardiac rehabilitation improves quality of life, aerobic capacity, and readmission rates in patients with chronic heart failure. Medicine (Baltimore), 2018, 97: e9629. [Medline] [CrossRef]

15) Song F, Zhan H, Liang Y, et al.: Cardiac rehabilitation improved oxygen uptake measured by cardiopulmonary exercise test in patients after aortic valve surgery. Rev Cardiovasc Med, 2019, 20: 47-52. [Medline] [CrossRef]

16) Gwoździński K, Pieniążek A, Czepas J, et al.: Cardiac rehabilitation improves the blood plasma properties of cardiac patients. Exp Biol Med (Maywood), 2016, 241: 1997-2006. [Medline] [CrossRef]

17) Nishitani M, Shimada K, Masaki M, et al.: Effect of cardiac rehabilitation on muscle mass, muscle strength, and exercise tolerance in diabetic patients after coronary artery bypass grafting. J Cardiol, 2013, 61: 216-221. [Medline] [CrossRef]

18) Vergès B, Patois-Vergès $B$, Cohen $M$, et al.: Effects of cardiac rehabilitation on exercise capacity in type 2 diabetic patients with coronary artery disease. Diabet Med, 2004, 21: 889-895. [Medline] [CrossRef]

19) Moreira H, Passos B, Rocha J, et al.: Cardiorespiratory fitness and body composition in postmenopausal women. J Hum Kinet, 2014, 43: 139-148. [Medline] [CrossRef]

20) Medici G, Mussi C, Fantuzzi AL, et al.: Accuracy of eight-polar bioelectrical impedance analysis for the assessment of total and appendicular body composition in peritoneal dialysis patients. Eur J Clin Nutr, 2005, 59: 932-937. [Medline] [CrossRef]

21) Wasywich CA, Whalley GA, Walsh HA, et al.: Changes in tissue-Doppler echocardiographic assessment of left ventricular filling during NT-proBNP guided heart failure treatment titration: a pilot study. Heart Lung Circ, 2009, 18: 38-44. [Medline] [CrossRef]

22) Svacinová $H$, Nováková $M$, Placheta $Z$, et al.: Benefit of combined cardiac rehabilitation on exercise capacity and cardiovascular parameters in patients with type 2 diabetes. Tohoku J Exp Med, 2008, 215: 103-111. [Medline] [CrossRef]

23) Eser P, Marcin T, Prescott E, et al.: Clinical outcomes after cardiac rehabilitation in elderly patients with and without diabetes mellitus: the EU-CaRE multicenter cohort study. Cardiovasc Diabetol, 2020, 19: 37. [Medline] [CrossRef]

24) Izawa K, Tanabe K, Omiya K, et al.: Impaired chronotropic response to exercise in acute myocardial infarction patients with type 2 diabetes mellitus. Jpn Heart J, 2003, 44: 187-199. [Medline] [CrossRef]

25) Schrauwen-Hinderling VB, Kooi ME, Hesselink MK, et al.: Impaired in vivo mitochondrial function but similar intramyocellular lipid content in patients with type 2 diabetes mellitus and BMI-matched control subjects. Diabetologia, 2007, 50: 113-120. [Medline] [CrossRef]

26) Szendroedi J, Schmid AI, Chmelik M, et al.: Muscle mitochondrial ATP synthesis and glucose transport/phosphorylation in type 2 diabetes. PLoS Med, 2007, 4: e154. [Medline] [CrossRef]

27) Barrès R, Osler ME, Yan J, et al.: Non-CpG methylation of the PGC-1alpha promoter through DNMT3B controls mitochondrial density. Cell Metab, 2009, 10: 189-198. [Medline] [CrossRef]

28) Phielix E, Mensink M: Type 2 diabetes mellitus and skeletal muscle metabolic function. Physiol Behav, 2008, 94: 252-258. [Medline] [CrossRef]

29) Sato S, Kato T, Otsuki S, et al.: Technetium- $99 \mathrm{~m}$ sestamibi retention in skeletal muscles, a potential indicator of mitochondrial function and anaerobic threshold in patients with type 2 diabetes. J Phys Fit Sports Med, 2015, 4: 223-229. [CrossRef]

30) DeFronzo RA, Tripathy D: Skeletal muscle insulin resistance is the primary defect in type 2 diabetes. Diabetes Care, 2009, 32: S157-S163. [Medline] [CrossRef]

31) Pedersen BK: Muscle as a secretory organ. Compr Physiol, 2013, 3: 1337-1362. [Medline]

32) Schnyder S, Handschin C: Skeletal muscle as an endocrine organ: PGC-1 $\alpha$, myokines and exercise. Bone, 2015, 80: 115-125. [Medline] [CrossRef]

33) Liu J, Li J, Li WJ, et al.: The role of uncoupling proteins in diabetes mellitus. J Diabetes Res, 2013, 2013: 585897. [Medline] [CrossRef]

34) Mootha VK, Lindgren CM, Eriksson KF, et al.: PGC-1alpha-responsive genes involved in oxidative phosphorylation are coordinately downregulated in human diabetes. Nat Genet, 2003, 34: 267-273. [Medline] [CrossRef]

35) Shi Y, Vanhoutte PM: Macro- and microvascular endothelial dysfunction in diabetes. J Diabetes, 2017, 9: 434-449. [Medline] [CrossRef]

36) Pratesi A, Tarantini F, Di Bari M: Skeletal muscle: an endocrine organ. Clin Cases Miner Bone Metab, 2013, 10: 11-14. [Medline]

37) Zane AC, Reiter DA, Shardell M, et al.: Muscle strength mediates the relationship between mitochondrial energetics and walking performance. Aging Cell, 2017, 16: 461-468. [Medline] [CrossRef]

38) Coen PM, Jubrias SA, Distefano G, et al.: Skeletal muscle mitochondrial energetics are associated with maximal aerobic capacity and walking speed in older adults. J Gerontol A Biol Sci Med Sci, 2013, 68: 447-455. [Medline] 